\title{
Elaboração e viabilização de uma aula sobre circunferência no ensino médio: um estudo de caso baseado na gênese documental
}

CHRYSTIAN BASTOS DE ALMEIDA ${ }^{1}$

CELINA APARECIDA ALMEIDA PEREIRA ABAR ${ }^{2}$

\begin{abstract}
Resumo
Este artigo visa a apresentar um estudo sobre o trabalho documental de um professor de Matemática do Ensino Médio e de um professor articulador de área, no processo de elaboração e viabilização de uma aula sobre circunferência, numa turma de $3^{a}$ série do Ensino Médio. Consideramos como principal base teórica a Gênese Documental, na qual a criação de um documento ocorre a partir de uma coletânea de recursos por apropriação e modificação pelo professor. Assim, em um intervalo de dois meses, em uma escola pública da rede estadual da Bahia, ocorreu a observação do trabalho do professor, organizado em três fases: antes, durante e depois de sua aula; através delas, procuramos discutir o uso dos recursos propostos pelo professor de Matemática e professor articulador para o ensino de circunferência. As conclusões do trabalho indicam expectativas teórico-metodológicas para a implementação de estudos na área da formação continuada docente, na direção da investigação reflexiva, sobre o uso de recursos para a viabilização da prática docente.
\end{abstract}

Palavras-chave: Gênese Documental; Circunferência; Formação continuada docente.

\begin{abstract}
This article aims to present a study on the documentary work of a high school mathematics teacher and of an area coordinator teacher, in the process of elaborating and making a circumference class feasible, in a 3 rd grade class in high school. We consider Documentary Genesis as the main theoretical basis, in which the creation of a document occurs from a collection of resources by appropriation and modification by the teacher. Thus, in an interval of two months, in a public school in the state network of Bahia, the work of the teacher was observed, organized in three phases: before, during and after his class; through them, we seek to discuss the use of resources proposed by the mathematics teacher and articulator teacher for teaching circumference. The conclusions of the work indicate theoretical and methodological expectations for the implementation of studies in the area of continuing teacher education, in the direction of reflective investigation, on the use of resources to make teaching practice feasible.
\end{abstract}

Keywords: Documentary Genesis; Circumference; Continuing teacher education.

\section{Introdução}

O desejo de aprimorar a interação entre os agentes envolvidos nas atividades de coordenação pedagógica de área do colégio (professor articulador e professor de

\footnotetext{
1 Pontifícia Universidade Católica de São Paulo. PEPG em Educação Matemática - e-mail: chrystian.bastos.irara@gmail.com.

2 Pontifícia Universidade Católica de São Paulo. PEPG em Educação Matemática - e-mail: abarcaap@pucsp.br.
} 
disciplina) tem sido recorrente na formação continuada de professores. Pois, nos momentos de coordenação pedagógica, os professores de disciplinas também têm a oportunidade de incrementar a sua formação continuada com o incentivo e colaboração do professor articulador.

Nesse sentido, esta pesquisa é estimulada por questionamentos sobre o impacto das sugestões de materiais didáticos e orientações dos professores articuladores aos professores regentes de Matemática, reportando-nos às contribuições que os professores articuladores podem oferecer aos professores regentes no desenvolvimento de seu trabalho documental. A pesquisa também é estimulada pela iniciativa em implementar uma avaliação, por parte do professor regente, do seu próprio fazer pedagógico, no que tange à elaboração de aulas e a sua viabilização em sala de aula.

Assim, destacamos o objetivo de apresentar um estudo sobre o trabalho documental de um professor de Matemática do Ensino Médio e de um professor articulador de área, no processo de elaboração e viabilização de uma aula sobre circunferência, numa turma de $3^{a}$ série do Ensino Médio. Convém salientar que o professor articulador de área é o primeiro autor desta pesquisa.

Para isso, traçou-se uma trajetória metodológica fundamentada na Gênese Documental, que apresenta como uma de suas particularidades considerar que o trabalho diário dos professores acontece tanto no contexto de sala de aula como em outros ambientes (em casa, na sala dos professores, na biblioteca, etc.). Levando em conta que, nessa abordagem, ocorre uma preocupação destacada com o uso de recursos na trajetória de elaboração das aulas e com o mecanismo de modificação destes no transcorrer do aperfeiçoamento da prática do professor.

Nesse caso, preocupamo-nos com práticas formativas elaboradas com este intuito. Assim, levando em conta que o uso de materiais recicláveis é atualmente valorizado nas atividades pedagógicas, pensamos que uma alternativa seria entender como os professores regentes de Matemática implementam sugestões didáticas em função deles e em associação com outros recursos mais usuais, como apostilas e softwares matemáticos.

Com o fim de analisar os recursos, a apropriação e adaptação que os professores regentes executam sobre eles e seus impactos na qualificação docente, implementamos 
um estudo de caso com um professor regente de Matemática em interação com um professor articulador de área. Tal estudo considerou o processo de formulação de uma atividade didática sobre o estudo da circunferência e consequente viabilização em sala de aula. Ele foi realizado em uma escola pública da rede estadual da Bahia e organizado em três fases: antes, durante e depois da aula. Todo o processo durou um intervalo de dois meses (entre setembro e outubro de 2018).

Destacamos a relevância da orientação do professor articulador em relação ao trabalho documental do professor regente de Matemática, tendo como suporte a apresentação de vários recursos alternativos (materiais recicláveis, softwares, etc.), assim como debates sobre a importância pedagógica desses materiais e a forma de articulação entre eles.

\section{Comentários sobre a Gênese Documental}

A Gênese Documental se preocupa com o fazer pedagógico dos professores começando com suas relações com vários materiais manipulados na trajetória de preparação de suas aulas. Conforme Gueudet e Trouche (2015), ela se baseia em vários referenciais conceituais, como a Teoria das Situações Didáticas de Brousseau, a Teoria Antropológica do Didático de Chevallard, a Teorias dos Campos Conceituais de Vergnaud e a Abordagem Instrumental de Rabardel.

Em relação à Teoria das Situações Didáticas, destaca Brousseau (1986):

Uma situação didática é um conjunto de relações estabelecidas explicitamente e ou implicitamente entre um aluno ou um grupo de alunos, num certo meio, compreendendo eventualmente instrumentos e objetos, e um sistema educativo (o professor) com a finalidade de possibilitar a estes alunos um saber constituído ou em vias de constituição [...]. O trabalho do aluno deveria, pelo menos, em parte, reproduzir características do trabalho científico propriamente dito, como garantia de uma construção efetiva de conhecimentos. (BROUSSEAU, 1986, p. 8).

Essa teoria favorece a análise sobre as interações entre os tópicos de ensino e as estratégias educacionais e, de forma mais geral, trata a didática como área de pesquisa cujo objeto é a divulgação dos conhecimentos matemáticos e suas modificações.

Sobre a Teoria Antropológica do Didático, destaca Almouloud (2015):

A Teoria Antropologia do Didático, segundo Chevallard, estuda o 
homem frente ao saber matemático, e mais especificamente, frente a situações matemáticas. Uma razão para a utilização do termo "antropológico" é que a TAD situa a atividade matemática e, em consequência, o estudo da matemática no âmbito do conjunto de atividades humanas e de instituições sociais. (ALMOULOUD, 2015, p. 10):

A Teoria Antropológica do Didático aborda a ideia de praxeologia que, segundo Chevallard (1999), trata dos conceitos de tipo de tarefa, técnica, tecnologia e teoria. Tais conceitos padronizam as atividades sociais em geral, inclusive as atividades matemáticas.

No tocante à Teoria dos Campos Conceituais, Vergnaud (1998) designa campo conceitual como um conjunto informal e heterogêneo de problemas, situações, conceitos, relações, estruturas, conteúdos e operações de pensamento, conectados uns aos outros e, provavelmente, entrelaçados durante o processo de aquisição.

Por essa abordagem, quando os alunos se deparam com novos contextos, eles procuram aplicar os conceitos obtidos em suas vivências anteriores, quando em contextos conhecidos e menos complexos, e procuram ajustá-los a esses novos.

Já em relação à Abordagem Instrumental, Rabardel (1995) destaca as interações existentes entre o sujeito, o artefato e os esquemas de utilização. Artefato é qualquer meio material (caderno, caneta, calculadora, etc.) ou simbólico (representação gráfica, tabela) sobre o qual o sujeito exerce uma ação. Segundo Vergnaud (1990), esquema é a organização invariante da conduta para uma classe de situações dadas, através da qual se devem investigar os conhecimentos em ato do sujeito, ou seja, os elementos cognitivos que permitem que essa ação seja operatória. Um esquema apresenta como um de seus componentes as invariantes operacionais, as quais envolvem conceitos em ação (aqueles considerados importantes) e teoremas em ação (enunciados considerados verdadeiros).

Gueudet e Trouche (2008, p. 6) comentam que a Abordagem Instrumental "tem sido usada em um grande número de pesquisas que utiliza estudantes como sujeitos e ferramentas digitais como artefatos". Ela envolve um processo chamado Gênese Instrumental, que busca entender de que forma um sujeito procede para obter um instrumento a partir de um artefato. Na gênese instrumental, dois mecanismos diferentes são considerados: a instrumentação e a instrumentalização. Sobre isso, comenta Bittar: 
Consideremos um professor para o qual o software é desconhecido. Ao entrar em contato com este material que não conhece, não sabe manipular nem mesmo as ferramentas básicas, este software é, para este professor, um artefato. À medida que ele começa a desvendar o material, descobrir como ele funciona e elaborar situações de uso do software, o professor está desenvolvendo e agregando ao artefato esquemas de utilização e, então, o artefato é transformado, para este professor, em instrumento. Quanto mais ele usar este instrumento, mais esquemas podem ser construídos, agregados ao software e o professor terá, então, um novo instrumento (BITTAR, 2011, p. 161).

Assim, quando o professor começa a desvendar o material, agregando ao artefato esquemas de utilização, ocorre o mecanismo da instrumentação; no momento em que mais esquemas vão sendo construídos, agregados ao instrumento, ocorre o mecanismo da instrumentalização. A Gênese Instrumental serve de apoio à Gênese Documental, cuja abordagem é de que a elaboração de um documento deriva de uma coletânea de recursos submetidos a etapas de apropriações, transformações, combinações, adaptações pelo professor.

De acordo com Gueudet e Trouche (2009), periodicamente, os recursos de um professor são atualizados, obtendo outros sentidos e outras maneiras de aplicação. Outros recursos começam a compor a sua coletânea e as interações com os alunos no contexto de sala de aula transformam e impactam a escolha e construção de atividades, inclusive seu planejamento pode ser alterado em função do diálogo com outros docentes. A esse grupo de procedimentos em que os docentes modificam de forma considerável seus materiais periodicamente, obtendo como resultado um documento, chama-se trabalho documental do professor.

Analisando a Figura 1, com o transcorrer da Gênese Documental, os recursos guiam a ação do docente (instrumentação) e, em contrapartida, o professor se apodera destes, ajustando-os e transformando-os no decorrer de sua utilização (instrumentalização). O termo recurso aqui é compreendido de forma abrangente, caracterizando tudo o que alimenta a ação do docente e seu aprimoramento pedagógico, como um material impresso, as bases legais da educação, um computador, um aplicativo, assim como uma produção dos alunos ou uma tarefa elaborada por outro professor. 
Figura 1 - Esquema da Gênese Documental

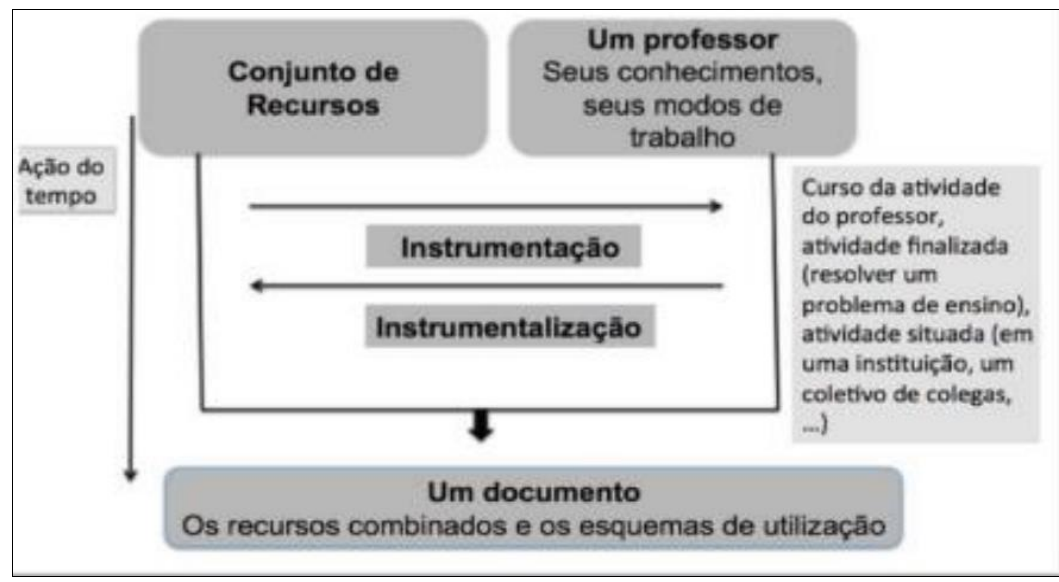

Fonte: Gueudet e Trouche (2015, p. 8).

Trouche (2016) esclarece que, assim como a abordagem instrumental diferencia o que está ao alcance para a atividade (os artefatos) e o que é elaborado pelos sujeitos (os instrumentos), a abordagem documental diferencia o que está ao alcance para a prática dos professores (os recursos) e o que eles elaboram para auxiliar a sua prática de ensino (os documentos). Assim, neste trabalho, analisamos os recursos, a apropriação e adaptação que um professor regente de Matemática executou sobre eles em interação com um professor articulador de área.

\section{Desenvolvimento da pesquisa}

Na primeira fase, antes da aula, a trajetória documental enfatizou a revisão do conteúdo combinado entre professor articulador e professor regente de Matemática: Estudo da Circunferência. Nesta fase, o professor articulador entrevistou o professor regente sobre os materiais que ele costumava utilizar para a elaboração de sua aula para uma turma da $3^{\text {a }}$ série do Ensino Médio, de uma escola pública estadual, na cidade de Irará - BA. Como resultado da entrevista, o professor regente deixou claro que costumava utilizar apenas apostilas, listas de exercícios, quadro-negro, giz e, eventualmente, vídeo-aulas.

Em razão da resposta dada pelo professor regente, o professor articulador procurou realizar um trabalho formativo sobre a importância de se utilizar outros recursos e estratégias para se trabalhar o conteúdo considerado, inclusive como forma de melhorar a motivação e desempenho dos estudantes. Foram travadas discussões entre o professor articulador e o professor regente sobre possíveis estratégias e recursos alternativos a serem adotados para o ensino da circunferência. Como resultado das discussões, ambos chegaram à conclusão de que seria interessante o uso de estratégias e recursos 
relacionados a temas de relevância na atualidade, como a sustentabilidade, além de algum software matemático como ferramenta auxiliar no processo de ensino.

Assim, definiu-se que o professor regente elaboraria seus planos de aula, buscando utilizar materiais recicláveis como pneus e o software GeoGebra, em articulação com os recursos habitualmente utilizados. Para isso, o professor regente teve a ideia de elaborar um projeto para as aulas, partindo do seguinte questionamento: "O estudo da circunferência, através da análise de pneus utilizados na construção de hortas nas escolas, pode favorecer uma melhor compreensão do conteúdo por parte dos alunos?”.

Então, o professor regente desenvolveu seu planejamento, destacando os conteúdos relativos ao estudo da circunferência que poderiam ser mobilizados nesse processo: raio de uma circunferência, diâmetro de uma circunferência, comprimento e área da circunferência, coordenadas do centro da circunferência, circunferências concêntricas, equações da circunferência, posições relativas entre circunferências, determinação experimental do valor de $\pi$, etc.

Na segunda fase, durante a implementação da atividade, o professor de Matemática trabalhou conteúdos relativos ao estudo da circunferência, articulando os recursos habitualmente utilizados (apostilas, listas de exercícios, quadro negro, giz, vídeo-aulas) com os novos recursos propostos (pneus utilizados na construção de hortas e o software GeoGebra); também aproveitou para fazer uma conexão com a disciplina de Biologia, discutindo com os alunos sobre as vantagens da construção de hortas com pneus, relativas à saúde, sustentabilidade e economia.

Numa perspectiva interdisciplinar, sob a supervisão do professor de Biologia, os alunos construíram as hortas no terreno do colégio (Figura 2), utilizando diversos tipos de pneus (de caminhão, carro, moto, carrinho de mão, etc.) e cultivando hortaliças, legumes, ervas, frutos ou flores ornamentais. A disposição dos pneus foi feita das mais diversas formas.

Figura 2 - Exemplo de horta com pneus

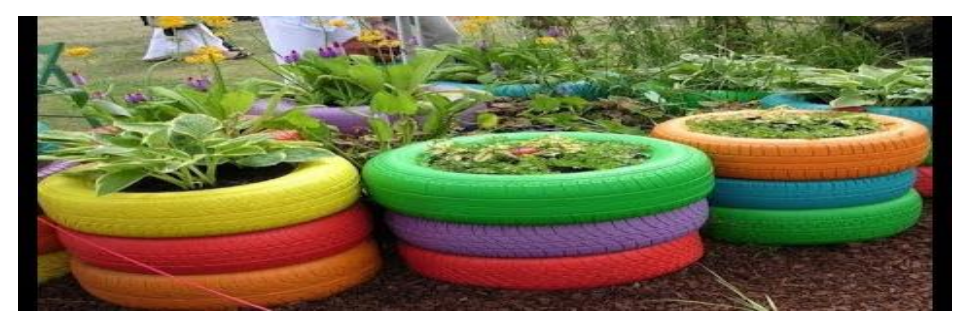

Fonte: Registrado pelo professor regente (2018). 
Enquanto trabalhavam na organização da horta, eles resolviam vários exercícios práticos relativos ao estudo da circunferência. O professor de Matemática solicitou, por exemplo, que eles determinassem o raio e o diâmetro de cada pneu; as equações da circunferência de cada pneu; o comprimento e a área das circunferências dos pneus; as posições relativas entre as circunferências dos pneus, assim como o valor experimental de $\pi$. Os exercícios elaborados pelo professor nas listas de exercícios foram resolvidos com o auxílio dos textos explicativos e exemplos das apostilas, assim como das orientações das vídeo-aulas sobre o conteúdo. A resolução dos exercícios ocorreu articuladamente de três formas: no ambiente lápis-papel; através de medição direta das grandezas dos pneus e através das ferramentas do software GeoGebra.

O Quadro 1 abaixo mostra alguns dos exercícios propostos pelo professor de Matemática nas listas de exercícios:

Quadro 1: Exemplos de exercícios sobre circunferência

Questão 1 - Determine o raio, o diâmetro, o comprimento e a área da circunferência de cada um dos pneus que você utilizou para a construção da horta. As medidas em centímetros podem ser aproximadas.

Questão 2 - Determine experimentalmente o valor aproximado de $\pi$, utilizando as medidas das grandezas dos pneus.

Questão 3 - Determine as equações das circunferências de cada um dos pneus que você utilizou para a construção da horta, considerando que eles sejam posicionados de forma a apresentarem o mesmo centro $\mathrm{C}(0,0)$.

Questão 4 - Faça a representação gráfica de cada uma das circunferências dos pneus que você utilizou para a construção da horta, utilizando as ferramentas do software GeoGebra.

Questão 5 - Posicione dois desses pneus, de forma que apresentem centros diferentes, determine a posição relativa entre as circunferências dos pneus e também faça a representação gráfica no GeoGebra.

Observação: a atividade deve ser realizada em duplas.

Fonte: Elaborado pelo professor regente (2018).

Cada dupla de alunos procurou executar a atividade mostrada no quadro acima, realizando as medições diretas das grandezas dos pneus, utilizando, por exemplo, fitas métricas. Para encontrar experimentalmente o valor aproximado de $\pi(3,14)$, os alunos 
efetuavam a divisão do valor do comprimento pela medida do diâmetro da circunferência de cada pneu. Para determinar a área da circunferência de cada pneu, os alunos efetuavam a multiplicação do valor de $\pi(3,14)$ pelo quadrado do raio da circunferência. O Quadro 2 abaixo mostra o resultado do trabalho realizado por uma das duplas de alunos:

Quadro 2: Respostas dos exercícios sobre circunferência

\begin{tabular}{|l|l|l|l|l|l|}
\hline Tipo de pneu & $\begin{array}{l}\text { Diâmetro } \\
(\mathrm{cm})\end{array}$ & $\begin{array}{l}\text { Raio } \\
(\mathrm{cm})\end{array}$ & $\begin{array}{l}\text { Comprimento } \\
(\mathrm{cm})\end{array}$ & $\begin{array}{l}\text { Área } \\
\left(\mathrm{cm}^{2}\right)\end{array}$ & $\begin{array}{l}\text { Equação } \\
\text { circunferência } \\
(\mathrm{x}-\mathrm{a})^{2}+(\mathrm{y}-\mathrm{b})^{2}=\mathrm{r}^{2}\end{array}$ \\
\hline Pneu A & 8 & 4 & 25,12 & 50,24 & $\mathrm{x}^{2}+\mathrm{y}^{2}=16$ \\
\hline Pneu B & 10 & 5 & 31,40 & 78,50 & $\mathrm{x}^{2}+\mathrm{y}^{2}=25$ \\
\hline Pneu C & 14 & 7 & 43,96 & 153,86 & $\mathrm{x}^{2}+\mathrm{y}^{2}=49$ \\
\hline
\end{tabular}

Fonte: Elaborado pelos alunos (2018).

Conforme solicitado nas listas de exercícios, os alunos também fizeram a representação gráfica das circunferências dos pneus, utilizando o software GeoGebra. A Figura 3 abaixo mostra a representação gráfica das circunferências relacionadas à tabela anterior:

Figura 3 - Representação de circunferências no GeoGebra

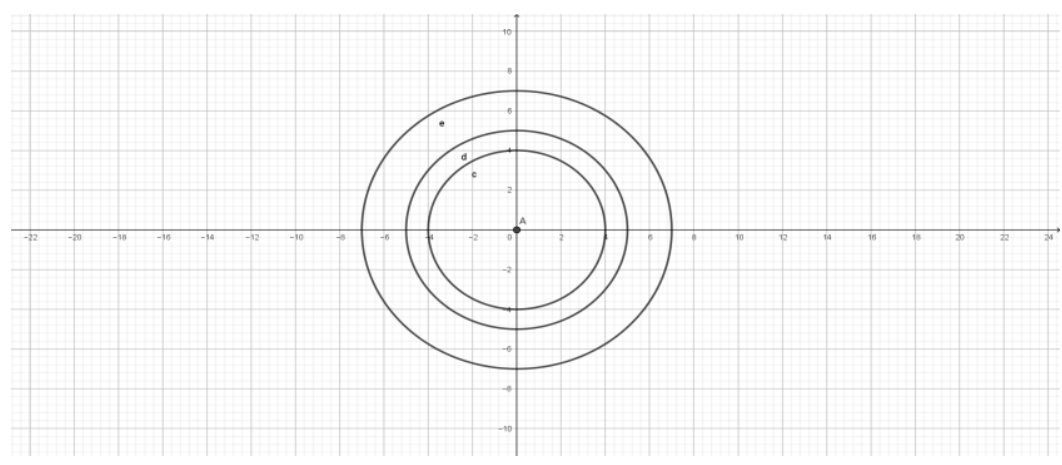

Fonte: Elaborada pelos alunos (2018).

Para responder à questão 5, a mesma dupla de alunos desenhou no chão do terreno um plano cartesiano, manteve a mesma posição do pneu A, cuja circunferência tem equação $\mathrm{x}^{2}+\mathrm{y}^{2}=16$ (centro na origem do plano) e mudou a posição do pneu $\mathrm{B}$, conferindo-lhe 
novo centro $C(9,0)$ e nova equação definida por $(x-9)^{2}+y^{2}=25$. Assim, verificaram que as circunferências dos dois pneus possuem somente um ponto em comum, sendo uma exterior à outra. Verificaram, também, que a condição para que isso ocorra é que a distância entre os centros das duas circunferências seja equivalente à soma das medidas de seus raios. Concluíram, então, que as circunferências dos dois pneus são tangentes externas. Também fizeram a representação gráfica da situação através do GeoGebra, conforme Figura 4 a seguir:

Figura 4 - Posições entre duas circunferências (tangentes externas) no GeoGebra

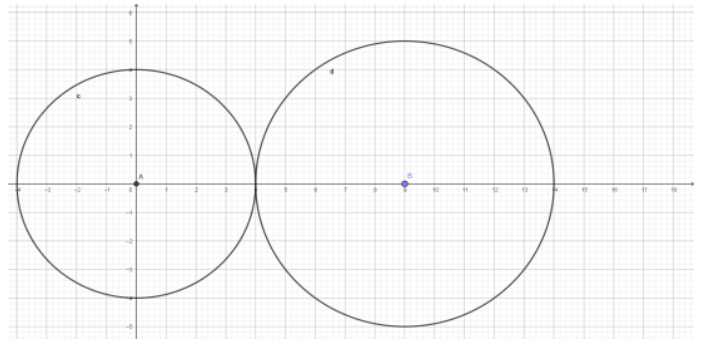

Fonte: Elaborada pelos alunos (2018).

$\mathrm{Na}$ terceira fase, depois da implementação da atividade, através de entrevistas e questionários, o professor de Matemática apurou o grau de satisfação dos alunos com a atividade, bem como aplicou testes para averiguar o nível de aproveitamento dos conteúdos, comparando com os resultados obtidos com a metodologia tradicional.

As entrevistas e questionários realizados com os alunos demonstraram um engajamento e um entusiasmo bem superiores aos demonstrados em atividades anteriores que não apresentaram os mesmos recursos e metodologia. Foram aplicados dois tipos de testes: um antes do processo, onde os conteúdos sobre circunferência foram abordados apenas com o uso de recursos habituais (apostilas, listas de exercícios, quadro-negro, giz e vídeo-aulas) e outro já no final das aulas, na terceira fase do desenvolvimento do trabalho, após a articulação entre os recursos habituais e os novos recursos propostos (pneus utilizados na construção de horta e software GeoGebra). O nível de rendimento obtido pelos alunos no último teste aplicado foi significativamente melhor que o obtido pelos alunos no primeiro teste, conforme constatou o professor regente.

Em relação ao questionamento feito pelo professor regente na primeira fase do desenvolvimento do trabalho, ele constatou que o estudo da circunferência, através da análise de pneus utilizados na construção de hortas nas escolas, pode favorecer uma 
melhor compreensão do conteúdo por parte dos alunos.

\section{Análise de resultados}

A investigação do trabalho documental do professor regente de Matemática em articulação com o professor articulador de área foi feita através da metodologia de investigação reflexiva (Gueudet e Trouche, 2012), através da qual registramos todo o processo de elaboração e viabilização da aula, durante um intervalo considerável de tempo (entre os meses de setembro e outubro de 2018). Essa investigação foi conduzida tanto no ambiente de sala de aula, quanto em outros ambientes (sala dos professores, biblioteca, laboratório de informática, etc.). A coleta de dados foi feita através de observações e anotações, destacando-se que o professor regente teve uma importante atuação nessa coleta, favorecendo o estudo do seu trabalho documental. O professor regente apresentou um relatório, fazendo reflexões sobre a contribuição da atividade desenvolvida para a sua qualificação profissional.

Fizemos a análise dos dados coletados, ao final da investigação, e verificamos os documentos desenvolvidos pelo professor regente em articulação com o professor articulador. O professor regente, anteriormente à investigação, desenvolveu seus próprios esquemas individuais, relativos ao ensino de circunferência. Por exemplo, com o objetivo "Encontrar a equação de uma circunferência, a partir do raio e coordenadas do centro", o professor havia desenvolvido um esquema que envolve o seguinte teorema em ação: "Os alunos devem determinar equações de circunferências, a partir de dados fornecidos pelas apostilas ou pelo professor no quadro negro".

$\mathrm{Na}$ interação com o professor articulador, o professor regente desenvolveu um outro teorema em ação: "Os alunos devem encontrar equações de circunferências, a partir da medição de grandezas das circunferências de pneus de hortas”. Em seguida, ao fazer o planejamento da aula, o professor regente incrementou seus invariantes operacionais com um novo teorema em ação: “Os alunos devem fazer a representação gráfica das circunferências dos pneus através do software GeoGebra". Assim, a interação com o professor articulador conduziu a determinadas evoluções nos invariantes operacionais do professor regente. 


\section{Considerações Finais}

Tendo como base a Gênese Documental, observamos esquemas de utilização de materiais recicláveis e do software GeoGebra que foram relevantes na atividade prática desenvolvida e constatamos invariantes operacionais, apresentadas pelo professor regente, de diferentes características: algébricas, geométricas, computacionais, etc. Em muitas atividades didáticas, o estudo da circunferência tem se limitado a desenvolver sugestões de apostilas e livros; no entanto, o desenvolvimento dessas atividades pode ser incrementado com a mobilização de outros tipos de conhecimentos, como o instrumental.

A visão detalhada sobre as origens dos recursos implementados pelo professor regente, em especial daquele sugerido pelo professor articulador (pneus para construção de horta) favoreceu, na atividade de coordenação pedagógica de área, uma análise sobre o mecanismo de elaboração do trabalho documental. Esse é o mecanismo através do qual um recurso derivado do professor articulador (pneus para construção de horta) passou a ser um recurso primitivo para o professor regente, tendo sido adaptado em associação com outros recursos primitivos (como o software GeoGebra) no desenvolvimento do recurso derivado do professor regente (coletânea de recursos integrados).

Tão relevante quanto nos familiarizarmos com o mecanismo de elaboração de um recurso derivado é nos familiarizarmos com as consequências de sua implementação em sala de aula e com a forma com que ele pode ser constantemente melhorado. Nesse sentido, pensamos que, quando o professor regente identifica o que necessita ser aperfeiçoado em seu trabalho docente, através dos recursos que ele se apropria, desenvolve, ajusta, modifica, isso favorece a sua qualificação docente.

Enfim, desejamos que a trajetória metodológica que mostramos, referenciada na Gênese Documental, possa incentivar novos estudos nessa área de formação continuada docente.

\section{Referências}

ALMOULOUD, S. A. Teoria Antropológica do Didático: metodologia de análise de materiais didáticos. Unión, v. 42, p. 09-34, 2015.

BITTAR, M. A abordagem instrumental para o estudo da integração da tecnologia na prática pedagógica do professor de matemática. Educar em revista, p. 157- 171, 2011. BROUSSEAU, G. Fondements et Méthodes de la Didactique des Mathématiques. 
Recherches em Didactique des Mathématiques, v. 7, n. 2, p. 33-116, 1986.

CHEVALLARD, Y. Analyse des pratiques enseignantes et didactique des mathematiques: l'approche anthropologique. Recherches em Didactique dês Mathématiques. v. 19, n.2, p. 221-26, 1999.

GUEUDET, G.; TROUCHE, L. Investigation réflexive des genèses documentaires des enseignants: vers une méthodologie pour l'analyse des genèses et des systèmes documentaires des enseignants. Lyon: Ifé, p. 1-14, 2008. Disponível em:

http://educmath.enslyon.fr/Educmath/recherche/approche_documentaire/methodo_appr ochedoc_dec08.pdf.

GUEUDET, G.; TROUCHE, L. Towards new documentation system for mathematicsteachers? The International Journal on Mathematics Education-ZDM, v. 71, p. 199-218, 2009.

GUEUDET, G.; TROUCHE, L. Teachers's work with Resources: Documentational Geneses and Professional Geneses. In: GUEUDET, G.; PEPIN, B.; TROUCHE, L. (Eds.). From Text to "Lived" Resources Mathematics Curriculum Materials and Teacher Development. Dordrecht: Springer, p. 23-41, 2012.

GUEUDET, G.; TROUCHE, L. Do trabalho documental dos professores: gêneses, coletivos, comunidades: o caso da Matemática. [Tradução de Katiane de Moraes ]. Em teia, v. 6, n. 3, 2015. Disponível em: https://periodicos.ufpe.br/revistas/emteia/article/view/2243.

RABARDEL, P. Les hommes et les technologies: une approche cognitive des instruments contemporains. Paris: Armand Colin, 1995.

TROUCHE, L. Compreender o trabalho do professor com os recursos de seu ensino, um questionamento didático e informático. In: SIMPÓSIO LATINO-AMERICANO DE DIDÁTICA DA MATEMÁTICA, 1., 2016, Bonito. Anais... Bonito, 2016, p.1-32.

VERGNAUD, G. La teoria de los campos conceptuales. [Traducción de Juan D. Godino. Espanha]. Recherches em Didactique dês Mathématiques, v. 10, p. 133- 170, 1990.

VERGNAUD, G. A comprehensive theory of representation for Mathematics Education. Journal of Mathematical Behavior, v. 2, n. 17, p. 167-181, 1998. 